\title{
MODEL KEPEMIMPINAN KRISTIANI BERBASIS TEOLOGI PERSAHABATAN
}

\author{
Alvian Apriano \\ Gereja Protestan di Indonesia bagian Barat \\ Jalan Medan Merdeka Timur 10, Jakarta Pusat 10110 \\ Email:alviapriano@gmail.com
}

\begin{abstract}
ABSTRAK: Dewasa ini, diskusi tentang model kepemimpinan kristiani umumnya diidentikan dengan model kepemimpinan pelayan yang diwariskan oleh Robert Greenleaf. Model kepemimpinan ini diklaim kontekstual, karena merepresentasikan model kepemimpinan Yesus yang dilaporkan kitab-kitab Injil. Padahal, Yesus juga menampilkan sisi persahabatan dalam model kepemimpinannya. Di dalam persoalan ini, muncullah pertanyaan-pertanyaan eksistensial-teologis, "Dapatkah kekristenan merealisasikan sebuah model kepemimpinan berbasis persahabatan? Seperti apa kekuatan dan kelemahannya? Bagaimana bentuk dan penerapan modelnya?" Pemikiran Liz Charmichael dan Steve Summers dengan analisa mereka yang kualitatif-teologis terhadap teori dan praktik persahabatan akan membantu menjawab pertanyaanpertanyaan tersebut. Pemikiran keduanya akan dielaborasi sehingga menghasilkan empat karakter pemimpin yang bersahabat. Makalah ini hendak menghadirkan model kepemimpinan kristiani berbasis teologi persahabatan berdasarkan penilaian kritis atas konsep kepemimpinan-pelayan guna memperluas khazanah kepemimpinan kristiani yang relevan baik di dalam komunitas gereja dan marketplace.
\end{abstract}

Kata Kunci: konsep persahabatan kristen, kepemimpinan kristiani, kepemimpinan pelayan, robert greenleaf, liz carmichael, steve summers, kepemimpinan bersahabat.

\section{CHRISTIAN LEADERSHIP MODELS BASED ON THE THEOLOGY OF FRIENDSHIP}

\begin{abstract}
Nowadays, the discussions on Christian leadership model are generally identified with the servant-leadership inherited by Robert Greenleaf. This model is claimed to be contextual because it represents Jesus's leadership model reported by the Gospels. However, Jesus also displayed friendship leadership model. In relation to this matter, existential-theological questions have appeared: "Can Christianity realize another leadership model based on the notions of friendship? What are the strengths and weaknesses? What is the form and how is the implementation?" The thoughts of Liz Charmichael and Steve Summers with their qualitative-theological analysis on friendship theory and practice will be helpful to answer these questions. The both thoughts will be elaborated to produce four characters of friendly leader. This article aims to present a Christian leadership model based on the notions of friendship theology by critically assessing the concept of servant-leadership in order to expand the Christian discourses of leadership model in church community and marketplace.
\end{abstract}

Keywords: the concept of christian friendship, christian leadership, servant leadership, robert greenleaf, liz carmichael, steve summers, friendship leadership. 


\section{PENDAHULUAN}

Di dalam diskursus kepemimpinan kristiani, pernyataan yang sangat familiar dari Robert Greenleaf ialah "pemimpin yang baik harus terlebih dahulu menjadi pelayan yang baik (Spears \& Lawrence, 2016, p. 10)." Argumen kunci Greenleaf ini telah memposisikan dirinya sebagai pelopor konsep pemimpin-pelayan dalam diskusi kepemimpinan dan terus diwariskan oleh Greenleaf Centre of Servant Leadership.

Akan tetapi, dalam perkembangannya konsep Greenleaf dicerna juga dalam konteks teologi Kristen dengan subjek kepemimpinan kristiani. Ken Blanchard adalah seorang analis yang berhasil menelusuri relevansi dari model pemimpin-pelayan ke dalam konteks gereja di Amerika (Brown \& Barker, 2001, p. 136). Pemikiran Blanchard ternyata diminati hingga ke Indonesia dengan banyaknya terjemahan dari publikasi Blanchard mengenai kepemimpinan di tokotoko buku Kristen maupun umum.

Di dalam konteks gereja di Indonesia, konsep pemimpin-pelayan telah menjadi semacam candu bagi para pemimpin Kristen di gereja. Masalahnya ialah model tersebut memberi ruang subordinasi dalam relasi (Adiprasetya, 2018, p. 48). Artinya, akan selalu ada labelisasi status atasan dan status bawahan. Padahal, komunitas gereja itu liquid, se-liquid kasih persahabatan Allah (Ward, 2013, pp. 1-2). Berdasarkan kecenderungan tersebut, maka diperlukan konsep alternatif kepemimpinan lainnya guna memperluas cakrawala kepemimpinan para pemimpin gereja di Indonesia.

Penelitian ini hendak menghadirkan model kepemimpinan kontekstual lainnya yang berbasis teologi persahabatan dengan mendialogkan pemikiran Robert Greenleaf, dengan Liz Carmichael, dan Steve Summers tanpa secara represif mengalienasi konsep kepemimpinan pelayan. Dengan demikian, diskusi kepemimpinan kristiani terus berada dalam pencarian model yang relevan sesuai tantangan zaman.

\section{METODE}

Penelitian ini akan mendeskripsikan secara teologis konsep kepemimpinan pelayan yang dominan dalam konteks kepemimpinan kristiani dan menganalisisnya secara kritis melalui konsep teologi persahabatan yang berkembang dalam teologi konstruktif. Sebagai realisasi praktis-konseptual, di akhir akan ditawarkan karakter pemimpin bersahabat guna mewarnai corak kepemimpinan baik di dalam komunitas gereja dan marketplace.

Metode yang ditempuh dalam penelitian ini ialah studi kualitatif yang berbasis pada teologi konstruktif tentang persahabatan. Data-data yang dideskripsikan, dieksplorasi dan dianalisis dikumpulkan melalui studi kepustakaan adalah yang related dengan judul penelitian ini. Karya-karya penting seperti teori Robert Greenleaf, penelitian Greenleaf Centre of Servant Leadership, dan konstruksi teologi konstruktif Liz Carmichael dan Steve Summers tentang tema persahabatan akan menjadi sumber primer dalam penelitian ini. Sementara tulisan-tulisan yang merupakan penelitian terdahulu tentang tema ini akan menjadi sumber sekunder.

\section{HASIL DAN PEMBAHASAN}

\section{Di Ambang Batas Kepemimpinan Pelayan Abad ke-21}

Di dalam konteks kontemporer, diskursus kepemimpinan kristiani masih tidak dapat melepaskan diri dari warisan Robert $\mathrm{K}$. Greenleaf, seorang pionir teori dan praktik kepemimpinan-pelayan dalam pelbagai bidang kehidupan. Ted Engestrom, Edward Dayton, dan Lee Harris, tiga orang tokoh yang aktif dan berfokus dalam diskursus kepemimpinan, baik dari segi teori, strategi, dan praktik, serta memperlihatkan relevansi dari konsep kepemimpinan-pelayan Greenleaf tersebut dengan merujuk karya-karyanya (Engestrom \& Dayton, 1976, p. 27). ${ }^{1}$ Pemahaman inilah yang melekat, sehingga tak jarang pola pikir ini diaplikasikan oleh 
sebagian pemimpin gereja di Amerika dan juga di Indonesia (Adiprasetya \& Sasongko, 2019, p. 21). ${ }^{2}$

Menurut Greenleaf, servant-leader atau pemimpin-pelayan,

... pertama-tama adalah seorang pelayan. Diawali dengan perasaan natural untuk menjadi pihak pertama yang melayani. Kemudian, kesadaran itu membawanya bercita-cita untuk memimpin. Perbedaan manifestasi dalam pelayanan yang diberikan, pertama adalah memastikan bahwa pihak lain dapat dipenuhi, yaitu menjadikan mereka sebagai orang-orang yang lebih dewasa, sehat, bebas, dan otonom, yang pada akhirnya dapat menciptakan pemimpin-pelayan yang berikutnya (Greenleaf, 2002, pp. 27-28). ${ }^{3}$

Kekuatan dari kepemimpinan-pelayan dibuktikan dengan berdirinya The Greenleaf Centre for Servant Leadership, suatu pusat pengembangan yang berfokus terhadap aspek-aspek kepemimpinan-pelayan. Komunitas ini memengaruhi banyak pihak terutama yang mendukung konsep kepemimpinan yang digagas oleh Greenleaf tersebut (Spears \& Lawrence, 2002, p. 370). ${ }^{4}$ Di dalam sebuah perayaan peringatan, mereka memublikasikan Focus on Leadership: Servant-Leadership for the Twenty-First Century sebagai wujud eksistensi akademik mereka sebagai sebuah komunitas berbasis riset.

Masing-masing penulis mengaitkan penelitiannya terhadap realitas di zaman ini dengan menunjukkan manfaat dari teori Greenleaf. Para penulis berasal dari latar belakang yang berbeda, tetapi menariknya, karya ini ditambahkan aspek kristiani dengan menghadirkan Ken Blanchard untuk memperlengkapi publikasi tersebut. Oleh karena itu, penelitian ini penting menginvestigasi aspek kristiani dari Robert Greenleaf manakah yang Ken Blanchard perlihatkan dalam kumpulan tulisan tersebut yang merupakan kekuatan dari teologinya.

Sebelum melihat uraian Blanchard ter- kait hal dalam karya tersebut, perlu diamati ketertarikan Blanchard dengan menganalisis secara istimewa karya-karya Greenleaf. Bahkan, ia memublikasi konsep pemikiran Greenleaf ke dalam The Servant Leader: Transforming Your Heart, Hands, and Habits (2003) dan menandai aspek-aspek yang diwariskan Greenleaf ke dalam konteks kepemipinan kristiani.

Publikasi ini berawal dari perjumpaan Blanchard secara langsung dengan Greenleaf di akhir tahun 1960, ketika berada di Universitas Ohio, Athena. la memperoleh masukan yang signifikan untuk penelitiannya tentang kepemimpinan, dan sangat tertarik dengan sumber-sumber dan sudut pandang ketika berinteraksi dengan Greenleaf secara langsung (Blanchard, 2002, p. $\mathrm{x})$.

Perjumpaan dan masukan pemikiran dari Greenleaf membuat Blanchard secara serius mengembangkan model kepempinanpelayan, namun dalam beberapa hal Blanchard mengelaborasinya dan menambahkan aspek kristiani di dalam investigasinya. Hal inilah yang terlihat dalam uraian Blanchard dalam karya bersama para penulis dari pusat studi Greenleaf. Blanchard adalah salah satu dari orangorang yang terlibat dalam pusat riset tersebut yang mengklaim bahwa kepemimpinan pelayan Greenleaf sangat bersifat aplikatif dalam konteks kepemimpinan kekinian. Baginya,

Not only are people looking for a deeper purpose and meaning when they must meet the challenges of today's changing world; they are also looking for principles and philosophies that actually work (Blanchard, 2002, pp. xi-xii).

Di dalam tulisan berjudul The Heart of Servant-Leadership, Blanchard menilai secara khusus relevansi dari kepemimpinanpelayan yang aplikatif melalui aktivitas Yesus yang patut diteladani. Bahkan ia telah bertahun-tahun mengajar dan memperdalam analisis kepemimpinan pelayan namun 
selalu jatuh ke dalam teladan Yesus. Blanchard menilai bahwa kekeliruan orang Kristen sering kali terletak pada status Yesus sebagai model spiritualitas saja, padahal tak ada yang lebih mendasar di dalam Alkitab bahwa model kepemimpinanlah yang diajarkan Yesus ke publik (Blanchard, 2002, p. xi).

Dari pernyataan tersebut, Blanchard menyadari bahwa Yesus pun mengembangkan dan memaksudkan kepemimpinanpelayan sebagai model dari kepemimpinannya dalam karya pelayanan bersama para murid. Bahkan Blanchard memanfaatkan pesan yang disampaikan Yesus kepada Yakobus dan Yohanes murid-Nya dalam Injil Matius,

Kamu tahu, bahwa pemerintah-pemerintah bangsa-bangsa memerintah rakyatnya dengan tangan besi dan pembesarpembesar menjalankan kuasanya dengan keras atas mereka. Tidaklah demikian di antara kamu. Barangsiapa ingin menjadi besar di antara kamu, hendaklah ia menjadi pelayanmu, dan barangsiapa ingin menjadi terkemuka di antara kamu, hendaklah ia menjadi hambamu (Matius 20:25-27).

Dari teks tersebut, Blanchard menafsirkannya ke dalam kerangka kepemimpinan kristiani. Menurutnya, Yesus sedang berbicara tentang kepemimpinan dan konsep kepemimpinan tersebut ada dalam rupa seorang pelayan. Blanchard menganggap bahwa Yesus tidak menawarkan model lain, melainkan kepemimpinan-pelayanlah satusatunya model yang relevan bagi-Nya dan bagi para murid (Blanchard, 2002, p. xi). Dengan demikian, terlihat dengan sangat jelas bahwa aspek kristiani yang Blanchard telusuri adalah Alkitab, secara khusus Injil Matius 20:25-27. Inilah pernyataan kunci Blanchard dalam uraiannya ini, yaitu memusatkan perhatian pada Yesus dan Alkitab yang merupakan bagian dari teologi fundamental Kristen untuk mengkonstruksi sebuah kepemimpinan kristiani berbasis kepemimpinan-pelayan.

Setelah melihat bagaimana kekuatan dari konsep kepemimpinan-pelayan, selanjutnya akan diperlihatkan kelemahan di dalamnya. Fokus penelitian ini adalah elaborasi aspek kristiani yang dipergunakan oleh Blanchard, ketika memposisikan teks Alkitab untuk menjelaskan konsep kepemimpinan-pelayan secara kristiani. Saya mencoba menempatkan tafsiran Richard France, sebagai seorang yang mendalami Perjanjian Baru dan memunculkan tafsiran yang cenderung baru terhadap Injil Matius dalam konteks yang Blanchard tafsirkan.

Di dalam menyoroti teks tersebut, France menegaskan bahwa teks ini harus dilihat dalam kerangka hasrat memperoleh harkat dan martabat yang lebih tinggi dalam pribadi seseorang (France, 2007, p. 755). Di dalam konteks percakapan Yesus tersebut, hasrat itu diperlihatkan oleh Ibu dari Zebedeus bersaudara (Yohanes dan Yakobus). Ibu mereka mencoba melakukan negosiasi dengan Yesus untuk menempatkan harkat dan martabat kedua anaknya menjadi lebih tinggi dari yang lainnya (France, 2007, pp. 756-757).

Lebih lanjut terkait dengan Matius 20:25-27 yang dikutip oleh Blanchard, France tidak secara tegas mengindikasi adanya deklarasi tentang kepemimpinan kristiani di sana, meskipun disebutkan kata pemerintah dan pembesar. Akan tetapi, keduanya adalah ilustrasi yang diucapkan Yesus untuk menunjukkan bahwa bahaya hasrat memperoleh harkat dan martabat yang lebih tinggi adalah otoriter (memerintah dengan tangan besi dan menjalankan kuasa dengan keras). Oleh karena itu, Yesus membicarakan hal menjadi pelayan dan melayani, menyoal harkat dan martabat pengikut-Nya (France, 2007, pp. 758-760). Dengan demikian, negosiasi tidak berlaku bagi Yesus, sehingga la juga tidak mendeklarasikan sebuah konsep kepemimpinan.

Kemudian, pertanyaan kritis yang muncul ialah apakah Blanchard menyadari 
bahwa terminologi pelayan (diakonos) di dalam Alkitab terhubung dengan relasi hamba (doulos) dan tuan? Bukankah kepemimpinan-pelayan akan menciptakan sebuah subordinasi, karena kecenderungan mencipta hierarki? Tidak adakah tempat bagi Blanchard bahwa dalam menambahkan aspek kristiani juga melihat makna kasih persahabatan Kristen yang disebutkan juga dalam Alkitab?

Blanchard memang tidak menjelaskan dan menguraikan bentuk dari kepemipinanpelayan di dalam karya bersama tersebut. Akan tetapi, di karya berikutnya (satu tahun setelah karya bersama itu), Blanchard menganalisis-tetap dalam pengaruh Yesus sebagai model-empat dimensi pemimpinpelayan. Analisisnya masih sangat dipengaruhi oleh tafsirnya atas teks yang di karya sebelumnya ia gunakan untuk menjelaskan kepemimpinan-pelayan secara alkitabiah. Analisisnya pun menyiratkan dilema subordinasi.

Indikasi adanya dilema tersebut nampak dalam uraian Blanchard dalam karyanya yang kemudian bersama Phil Hodges, namun jika dicermati maka tafsiran Blanchardlah yang dominan di sana. Menurut Blanchard dalam pengaruh konsep kepemimpinan pelayan, pemimpin-pelayan mencakup empat dimensi karakter, yakni hati, kepala, tangan dan kebiasaan. Pertama, dimensi hati, yakni ketika seorang pemimpin yang melepaskan self-serving dan ego untuk mendukung, dan selalu setia terhadap yang dipimpinnya, memiliki kerendahan hati, karena itu ia tidak berpusat pada dirinya sendiri melainkan kepada orang yang dipimpinnya (Blanchard \& Hodges, 2003, pp. 16-20).

Kedua, dimensi kepala, yakni ketika seorang pemimpin menjadi sangat visioner. Visinya dapat ia jelaskan kepada yang lain, kemudian ia melakukan hal yang benar dan memproses visinya hingga memperoleh hasil yang juga benar (Blanchard \& Hodges, 2003, pp. 40-45). Ketiga, Dimensi tangan berarti bahwa ia memproses visinya dengan tangannya untuk memperoleh hasil yang maksimal. la juga menolong rencana orang yang dipimpinnya tetapi dengan cara melatih hingga potensi yang dipimpinnya muncul untuk memproses visinya sendiri. Keempat, dimensi kebiasaan, yakni mengembangkan kebiasaan dan perilaku, pemimpin disiplin dan merawat hubungan yang baik dengan yang dipimpinnya. Dengan demikian, ia dapat mengubah kultur dalam organisasinya (Blanchard \& Hodges, 2003, pp. 80-84).

Setelah melihat keempat dimensi karakter tersebut, terlihat suatu dilema subordinasi yang kental, yakni ketika seorang pemimpin sedang melayani orang yang dipimpinnya, maka konsekuensi logisnya adalah yang dilayani akan melayani pemimpinnya juga dan inilah kultur yang dibangun dalam konsep tersebut. Inilah kritik yang dapat digarisbawahi atas keempat dimensi tersebut.

Sementara itu, konsep Greenleaf sendiri telah menimbulkan penilaian kritis di kalangan komunitas gereja, karena konsep Greenleaf tentang kepemimpinan membuka ruang terhadap pola subordinasi dalam relasi. ${ }^{5}$ Namun demikian, tidak berhenti sampai di situ saja. Permasalahan penelitian ini adalah seperti yang dikemukakan oleh Adiprasetya bahwa praktik kepemimpinanpelayan tersebut menjadi bagian dalam kehidupan bergereja di Indonesia yang ditunjukkan oleh para pendetanya.

Bagi Adiprasetya, dalam konsep kepemimpinan-pelayan tampak adanya subordinasi (Adiprasetya \& Sasongko, 2019, p. 22). Padahal, peradaban sekarang ini sudah tidak menekankan lagi subordinasi. la melihat bahwa sifat pastoral kepemimpinan kristiani hilang di banyak gereja. Fokusnya beralih ke peristiwa liturgi yang kudus. Dengan demikian, pemimpin pelayan atau dalam istilah Adiprasetya adalah doularchy terus menerus dipraktikkan setiap hari (Adiprasetya, 2018, p. 48) tanpa membuka ruang untuk memetakan model kepemimpinan kontekstual lainnya. 
Dengan memperhatikan penilaian kritis komunitas gerejawi atas konsep Greenleaf dan argumen kunci Adiprasetya yang berbentuk keprihatinan terhadap para pemimpin gereja, investigasi ini perlu juga menjadi sumbangan yang relevan bagi diskursus kepemimpinan kristiani. Namun, tidak terutama kepada pendeta melainkan para pemimpin dalam komunitas gereja karena partisipan kepemipinan di gereja tidak hanya seorang pendeta. Oleh karena itu, perhatian berikutnya ialah kepada diskusi yang baru-baru ini berkembang, yakni konsep persahabatan yang inheren dengan kepemimpinan kristiani, sembari mencoba melihat dalam hal apakah konsep persahabatan Kristen dapat memberikan sumbangan dalam tujuan penelitian ini.

\section{Konstruksi Teologi Carmichael dan Summers Tentang Persahabatan}

Telah disebutkan sebelumnya bahwa terlebih dahulu akan ditelusuri teks Yohanes yang memperbincangkan tentang persahabatan. Di sini, akan secara khusus memfokuskan perhatian kepada Liz Carmichael dan Steve Summers, dua orang teolog yang berfokus kepada tema persahabatan. Menariknya, karya keduanya yang dipublikasikan sekitar tahun 2000-an menjadi cukup dominan memperlihatkan tema-tema persahabatan. Beberapa terbitan antara lain: Friendship: Interpreting Christian Love (2004), Friendship: Exploring its Implications for the Church in Postmodernity (2009), Politics in Friendship: A Theological Account (2014). Akan tetapi, di sini hanya akan ditelusuri kedua karya yang relevan dengan permasalahan utama, dan yang menjadi fokus di dalamnya.

Penelusuran tersebut dimulai dari Liz Carmichael, seorang pendeta kampus dan pengajar di St. John College, Oxford yang menginvestigasi terminologi kasih Kristen dalam kaitannya dengan persahabatan. Di dalam bukunya, Friendship: Interpreting Christian Love, Carmichael mencoba mengeksplorasi makna kasih Kristen, yakni kasih persahabatan. Persahabatan digambarkan sebagai sebuah model hubungan, yakni kasih dan memungkinkan setiap orang untuk meninjau sifat dasarnya. Carmichael memang tidak memberi pembatasan definisi terkait persahabatan namun dia mencirikan bahwa persahabatan merupakan suatu relasi resiprokal antarpersonal. Tujuannya adalah memberikan gambaran beragam tentang bagaimana setiap orang akan memikirkan dan melatih kasih kristiani sebagai kasih persahabatan dengan menelusuri tradisi kekristenan tentang persahabatan sendiri (Charmichael, 2004, pp. 4-5).

Sementara itu, Steve Summers, seorang pengajar dan pendeta Jemaat di gereja Anglikan mengelaborasi persahabatan dalam rangka mewujudkan basis eklesiologis di antara gereja-gereja dalam konteks posmodernisme. Lebih lanjut ia ingin mengusulkan bahwa persahabatan dapat menjadi basis yang sangat kuat dan penting untuk gereja dalam memahami dirinya yang hadir untuk menekankan relasionalitas. Persahabatan adalah suatu relasi yang kuat dan merangkul perbedaan, mencari kebaikan dari yang lain dalam mutualitas yang resiprokal. Menurutnya, model inilah yang akan menjawab tantangan zaman (Summers, 2009, pp. 1-2).

Urgensi keduanya pun berbeda. Summers lebih melihat gereja yang kurang melihat persahabatan sebagai basis eklesiologi yang penting, sementara Carmichael terpikat dengan penelusuran Jurgen Moltmann yang sampai kepada kesimpulan bahwa persahabatan merupakan "universal invitation to the messianic feast, and yet specifically personal and welcoming."6 Oleh karena itu, perlu ditelusuri latar belakang tulisan keduanya di sini. Karya mereka ini tergolong ke dalam metode deskriptif, karena mereka memiliki fokus untuk menjelaskan alur berteologi tokoh-tokoh yang mereka pilih dan kemudian merumuskan pemaknaan masing-masing. Dengan demikian, perlu dicermati pemikiran keduanya di 
bagian-bagian akhir dalam tulisannya.

Keduanya, mengawali penelusuran mereka atas teks Yohanes, meskipun secara khusus Carmichael tidak melepaskan konteks zaman sebelum Perjanjian Baru. Oleh karena itu, kembali lagi ke pemikiran kunci Carmichael terlebih dahulu. Menurutnya, teolog Kristen telah mendiskusikan kasih dan persahabatan dalam konteks kultural Yunani. Sementara konteks sebelumnya (para filsuf) bergerak dari kasih sebagai pemersatu harmonisasi kosmik sebagai syarat persahabatan pribadi dalam hubungan antar umat manusia (Carmichael, 2004, p. 7).

Di dalam Alkitab, kasih menjadi tema sentral hingga ketika Yesus memberikan "perintah baru" untuk mengasihi satu dengan yang lainnya, "seperti Aku mengasihi kamu (Yoh.13:34; 15:12)." Di sini terlihat bahwa kasih telah menjadi penentu diskusi tentang persahabatan Kristen. ${ }^{7}$

Setelah melihat bagaimana Carmichael mendasari pemikirannya, selanjutnya akan melihat Summers menginvestigasi kesamaan landasan ini. Analisis Summers hampir senada dengan Carmichael bahwa titik berangkatnya adalah Yohanes 15, karena aspek tekstual persahabatan secara eksplisit berasal dari tradisi ini, bahkan Summers menambahkan istilah transformasional untuk teks yang bersifat percakapan ini (Summers, 2009, pp. 9-10). Setelah melihat aspek alkitabiah ini, penulis akan mempelihatkan bagaimana secara konstruktif tema ini dieksplorasi oleh Carmichael dan Summers.

Carmichael menelusuri para teolog klasik yang memberikan sumbangsih terhadap tema ini. Akan tetapi, konteks yang menarik dan relevan baginya adalah Aelerd dari Rievaulx. ${ }^{8}$ Aelerd disoroti oleh Carmichael, karena sumbangsih pemikiran Aelerd terkait ini memiliki signifikansi yang kuat. Namun demikian, tokoh-tokoh seperti Ambrosius, John Cassian, Agustinus, Thomas Aquinas, yang membangkitkan diskursus ini juga disoroti, bahkan para filsuf seperti Kant dan Kierkegaard diberikan tempat untuk memperlihatkan relevansinya kini. Summers juga menelusuri mereka, karena memang ia berada dalam pengaruh Carmichael. $^{9}$ Akan tetapi, Summers lebih banyak memberikan tempat terhadap para filsuf klasik yang memang mengawali diskursus ini, seperti Aristoteles dan Cicero.

Namun demikian, penelitian ini hanya akan berfokus untuk mengikuti pemikiran kunci Carmichael dan Summers dalam konstruksi mereka atas konsep persahabatan Kristen. Oleh karena itu, perlu diketahui fokus kedua teolog tersebut, karena tulisan keduanya berbentuk deskriptif, sehingga secara sistematis mereka menguraikan para teolog dan juga beberapa filsuf yang membicarakan tema ini.

Pertama, dimulai dari Carmichael. Di dalam konteksnya sebagai seorang pendeta kampus dan pengajar, pemikiran Carmichael sangat berorientasi kepada perkembangan investigasi tentang tema kasih Kristen ke dalam relevansinya bagi gaya hidup kekristenan kontemporer. Pertanyaan yang kemudian muncul adalah apakah Carmichael mengarahkan pemikirannya ke kepemimpinan-sahabat. Memang tidak secara eksplisit, tetapi ia menempatkan seorang pemimpin gereja sebagai refleksi teologisnya.

Carmichael merefleksikan sosok John Swinton seorang teolog yang berfokus pada disabilitas dan merupakan pendeta di Church of Scotland. Swinton menunjukkan model pendeta yang bersahabat. la menulis tentang orang-orang yang hidup "berkebutuhan khusus" dan berharap agar umat awam di gereja lokal dapat menerima dengan persahabatan, meskipun sulit. Bagi Swinton, menjadi sahabat ialah menjangkau pribadinya, bukan menjustifikasi apa yang dialaminya (Carmichael, 2004, pp. 196-197). Carmichael terpikat dengan sosok kepemimpinan Swinton yang menurutnya dilandasi oleh persahabatan. Baginya,

“... as a pastor, John Swinton has assisted 
people to discover how to make unusual friendship, to be channels of the friendship-love of Christ." [Menurut Carmichael, Swinton semakin menegaskan bahwa] Christian have the essential counter-cultural calling to be friends on earth, to offer love which may be in the truest sense sacrificial, to build community, to be peacemakers and healers, to seek and promote compassion and justice, to walk with the oppressed and help their voice to be heard, to celebrate with all (Carmichael, 2004, pp. 196-197).

Prinsip Swinton inilah yang membuat Carmichael terpikat untuk mengukuhkan konsep persahabatannya juga ke dalam aspek kepemimpinan sehingga ia juga menyemai visi eklesiologis dalam karyanya tersebut.

Dari pernyataan reflektif yang ditandai oleh Carmichael tersebut diperlihatkan bahwa model kepemimpinan Swinton adalah realisasi pemimpin yang bersahabat. Carmichael juga menilai bahwa,

The praxis of friendship requires that in addition to forming friendships with people close by, we should make efforts to cultivate a much wider network of deepening friendships in different continents and cultures, from which to gain understanding ... with respect and sensivity (Carmichael, 2004, p. 199).

Nilai praktis yang penting ini memperlihatkan kecenderungan ciri bahwa persahabatan akan menghasilkan sebuah tatanan yang aktif dan reaktif, serta menguatkan.

Sementara itu, Summers lebih melihat aspek persahabatan ini relevan dalam konteks eklesiologi. la berada dalam imajinasi dan cita-cita untuk mengembangkan sebuah komunitas berbasis persahabatan. Memang tujuan dari tulisannya ini adalah memberikan implikasi yang mendarat dalam konteks gerejawi. Hal ini tidak lepas dari latar belakangannya sebagai seorang pendeta jemaat di gereja. Urgensitasnya adalah menciptakan sebuah basis yang menjawab tantangan posmodernitas (Summers, 2009, p. 192). Pertanyaan yang muncul kemudian adalah apakah Summers juga mengarahkan pola pikir tentang kepemimpinan yang bersahabat?

Pertanyaan tersebut dapat dijawab apabila menandai bahwa Summers melihat persahabatan dalam bingkai relasionalitas bahkan pola inilah yang akan menciptakan eklesiologi yang bersahabat. Bagi Summers, konsep persahabatan akan menjadi sebuah tawaran menarik bagi gereja di zaman postmodern yang menuntut citra diri dan sifat komunitas gereja agar tidak jatuh ke dalam relativisme. Konsep ini akan mewadahi pencarian 'the good of 'the other' and encouraging the friend to be another self" (Summers, 2009, p.194).

Sampai di sini terlihat jelas bahwa kesetaraan setiap anggota menjadi dasar dari tujuan komunitas. Termasuk gereja yang memungkinkan persahabatan untuk berkembang dan bertumbuh subur di tengah keberagaman citra diri. Kualitas kesetaraan dan saling mendorong ke arah yang lebih baik menjadi faktor mendasar untuk tercapainya pola relasi persahabatan. Ini yang dibutuhkan gereja dan para pemimpin masa kini di dalam rangka mengembangkan eklesiologi yang diwarnai nilai relasi persahabatan.

\section{Analisis Teologi Carmichael dan Summers tentang Persahabatan dalam bingkai Kepemimpinan}

Dalam diskursus eklesiologi, faktor penggerak dari relasi persahabatan ialah kepemimpinan. Kepemimpinan merupakan bagian dari eklesiologi, dan kepemimpinan merupakan bagian yang penting dalam sebuah tatanan gerejawi yang dapat membawa jemaat ke dalam partisipasi di dalam gereja (Hendriks, 2002, pp. 66-67).

Dari konstruksi teologi persahabatan Carmichael dan Summers terlihat adanya fokus atau perhatian yang sama ketika 
mencoba menempatkan konsep ini dalam bingkai yang lebih praktis. Jika diperhatikan, maka hal tersebut nampak tatkala keduanya menandai faktor praktis sosok pemimpin yang mempengaruhi tinjauan ilmiah-teologis mereka tentang konsep persahabatan kristiani (Carmichael, 2004, p. 196; Summers, 2009, p. 23).

Ada upaya implementasi dari konsep yang mereka bangun berkaitan dengan pemimpin yang memimpin dengan pendekatan persahabatan. Oleh karena itu, konsep persahabatan Carmichael dan Summers bukanlah sebuah teologi yang bersifat statis dan menutup kemungkinan untuk diterapkan ke dalam aspek-aspek kehidupan lainnya, melainkan teologi yang bersifat dinamis dan terbuka untuk diaplikasikan ke dalam sendi-sendi eklesiologis. Termasuk kepemimpinan, karena di sinilah relasionalitas tercipta.

Misalnya saja sorotan keduanya terhadap sosok pemimpin dalam komunitas gereja. Bagi keduanya, pemimpin sangat mempengaruhi gerak persahabatan baik secara pribadi maupun eklesiologis, sehingga keduanya membuka peluang untuk mengembangkan modeling dan profiling pemimpin yang bersahabat dalam bingkai kepemimpinan di komunitas gereja.

Tidak hanya itu, secara teologis keduanya juga saling memperlengkapi dan menjelaskan, karena argumen kunci mereka berdua dalam karyanya yang disoroti dalam penelitian ini, berdasarkan teladan sikap dan karakter relasi Yesus dengan para murid dan orang banyak yang menjumpainya. Carmichael dan Summers menandai Injil Yohanes 13-14. Dalam perjalanan pelayanan Yesus, la menjalin relasi dengan para murid-Nya. la menganggap muridmurid bukanlah seseorang yang lebih rendah dari diri-Nya tetapi la menganggap para murid sebagai sahabat.

Bagi Summers, pada saat itu, Yesus merupakan guru bagi murid-murid-Nya karena itulah gelar yang diberikan kepada-Nya (Summers, 2009, p. 23). Ketika dianggap sebagai seorang guru oleh para murid, Yesus dengan kerendahan hati-Nya malah membasuh kaki mereka dan menyebut para murid-murid-Nya sebagai sahabat-Nya (Summers, 2009, p. 23).

Secara eksplisit, Carmichael pun menandai bahwa Yesus tidak ingin para murid menganggap diri-Nya lebih tinggi dari para murid. Oleh karena itulah, Yesus menginisiasi persahabatan dengan mereka (Carmichael, 2004, p. 162). Berdasarkan konstruksi teologi persahabatan dari kedua teori utama dalam penelitian ini, dapat dinilai bahwa faktor sikap dan karakter serta relasionalitas menjadi basis terciptanya kepemimpinan bersahabat dalam komunitas kristiani. Gereja merupakan salah satu ruang lingkupnya. Tanpa ruang lingkup maka teologi persahabatan hanya bersifat spiritual dan tidak mewujud ke dalam praktik berteologi yang konkrit.

Sampai di sini, dapat digarisbawahi bahwa teologi persahabatan adalah sebuah teologi yang berbasis relasionalitas. Allah yang telah bersahabat kepada manusia, karena itu sebagai respons mutual, manusia perlu bersahabat dengan sesamanya (Levering, 2007, p. 39-40). Dengan demikian, pertanyaan terakhir yang akan menutup penelitian ini ialah bagaimana bentuk dan implikasi model tersebut di dalam konteks komunitas kristiani? Baik gereja maupun marketplace. Bagian berikutnya akan memberikan ciri dan karakter kepemimpinan yang bersahabat.

\section{Implikasi Teologi Persahabatan Bagi Diskursus Kepemimpinan Kristiani}

Seperti yang telah diperlihatkan di bagian pendahuluan bahwa diskursus kepemimpinan kristiani memang banyak dipengaruhi oleh konsep kepemimpinanpelayan. Kenyataan ini dibuktikan dengan beberapa pemahaman yang dihasilkan dari pengaruh mendalami konsep kepemimpinan-pelayan. Akan tetapi, setelah menelusuri konstruksi teologi persahabatan yang ada, terlihat ada kecenderungan lain untuk 
menambah sumbangan terhadap diskursus kepemimpinan kristiani, yakni kepemimpinan yang bersahabat.

Bukan berarti kepemimpinan-pelayan harus serta merta diganti, tetapi wawasan komunitas gereja sebaiknya semakin ditambah melihat zaman yang fleksibel dan longgar subordinasi ini. Khususnya, dalam memanfaatkan ruang interaksi digital, kepemimpinan bersahabat akan menghubungkan dirinya sebagai seorang sahabat. Oleh karena itu, pertanyaan terakhir akan dijawab dengan menguraikan bentuknya. Karena itu, penting untuk memperlihatkan karakteristik apakah yang akan muncul dalam konsep kepemimpinan-sahabat, sekaligus meninjau juga kelebihan dan kekurangannya. Carmichael dan Summers telah memperlihatkan pemahaman teologis tentang persahabatan, dan ada kemungkinan untuk mengkonstruksi sebuah konsep kepemimpinan bersahabat berbasis relasi kasih persahabatan.

Dengan demikian, kepemimpinan kristiani memiliki peluang untuk menempatkan model kepemimpinan bersahabat dengan pendeta sebagai pemimpinnya (Jackson, 2016, p. 156). Apakah konsep ini akan mengganti pretensi dari kepemimpinanpelayan yang telah mempengaruhi pola kepemimpinan gerejawi? Tentu tidak sebagaimana telah ditekankan di atas. Akan tetapi, konsep ini akan menambah wawasan gereja bahwa keberadaannya di dunia, tidak hanya tentang melayani, tetapi juga menjadi sahabat.

Kini gereja ada di zaman yang tidak lagi menekankan subordinasi, sehingga apabila terbentuk konsep kepemimpinan bersahabat, maka gereja akan menjadi inspirasi bagi komunitas lainnya. Berdasarkan gagasan tersebut, maka dapat didefinisikan bahwa kepemimpinan bersahabat merupakan sebuah cara menggapai tujuan bersama dalam gereja, ketika kasih membuat pemimpin mengaktualisasikan diri sebagai sahabat bagi anggotanya.

Relasinya menjadi timbal balik, dan berada pada sebuah kesetaraan dan dorongan-dorongan yang menghasilkan manfaat dalam tujuan bersama yang efektif. Berdasarkan definisi ini, kepemimpinan bersahabat perlu diperlengkapi oleh karakter pemimpinnya yang mampu juga memfasilitasi ingatan negatif di masa lalu yang sempat membatasi relasi (Pakpahan, 2017, p. 236).

Penelitian ini mengusulkan empat karakter seorang pemimpin bersahabat dengan tetap berada dalam pengaruh dari Carmichael dan Summers, sembari mencoba memperlihatkan kekurangannya.

Pertama, seorang pemimpin bersahabat adalah seorang yang mampu melewati batas-batas. Batas-batas yang dimaksudkan di sini adalah usia dan menerima pribadi lain yang asing baginya. Teladannya adalah Yesus, yang mau bersahabat dengan para murid, anak kecil, perempuan, para marjinal, disabilitas serta orang-orang asing lainnya. Di sini, pemimpin tidak hanya membuka pemahamannya terhadap golongan tersebut, tetapi bersedia berdialog dan menganggap serta menerima bahwa mereka ada. Kekurangannya di sini ialah apabila terpola, pemimpin dapat beralih fokus dalam orientasinya, yakni perhatian lebih kepada kalangan orang terpinggirkan, sehingga menimbulkan kecemburuan sosial bagi anggota sebagai perhatian awal, karena tidak lagi menjadi prioritas.

Kedua, mencari potensi dari anggota dan memberikan harapan untuk menjadi pribadi yang berubah. Di sini, pemimpin berperan sebagai agent of change bukan bagi dunia tetapi bagi anggotanya, dengan melihat potensi dari diri anggotanya untuk transformasi dirinya ke depan sehingga menjadi pemimpin juga berarti mempersiapkan kader-kader potensial berikutnya yang dapat meneruskan tongkat pelayanan. Kekurangannya di sini ialah pemimpin akan sibuk menggali potensi anggotanya, namun lupa untuk menggali potensinya sendiri dan tanggung jawab yang masih dimilikinya, sehingga relasi resiprokalnya menjadi satu arah dan dapat hilang. Oleh karena itu, 
anggotanya perlu memiliki kesadaran untuk menjadi kader lanjutan dengan meneladani upaya pemimpin sehingga mau turut berperan sebagai penggali potensi di tengah komunitas.

Ketiga, pendamai. Di sini pemimpin menjalankan panggilan pastoralnya (Apriano, 2018, p. 93). ${ }^{10}$ Di dalam pengaruh kasih persahabatan dia tidak lagi menjadi seorang yang membawa gaduh dalam pertemuan, apabila berbeda pendapat, tetapi membawa gaung perdamaian dengan mengafirmasi insight pendapat lainnya. Di sini, akan muncul kekurangan bahwa pemimpin menerima segala insight namun menjadi lupa bahwa ia juga memiliki insight lain yang dapat dielaborasi dengan insight yang ada. Bahkan, di sini ia dapat mengangkat ingatan-ingatan negatif di masa lalu untuk menata masa depan berkomunitas dengan lebih baik.

Keempat, compassion. Dalam pengertian ini, pemimpin sadar untuk menghibur orang lain yang dipimpinnya. Terkhusus, dalam relasinya dengan anak-anak, remaja dan pemuda yang sering kali melihat diri pemimpin sebagai seorang senior yang patut disegani, karena dia adalah pemimpin di komunitasnya. Dengan karakter ini, pemimpin menjadi youth minister yang dekat dengan mereka. Di sini, apabila relasinya dipahami begitu ekstrem, maka pemimpin dapat dianggap sebagai teman sebaya dan mesti mengikuti segala aktivitas di masa kecil atau muda mereka yang notabene sudah dilalui olehnya. Oleh karena itu, pemimpin juga perlu mempertimbangkan pola relasi yang lebih berwibawa agar tidak jauh jatuh ke dalam ekstrem tersebut.

\section{KESIMPULAN}

Penelitian ini telah mengakhiri alur berteologi tentang persahabatan dan juga

\section{DAFTAR RUJUKAN}

Adiprasetya, J., \& Sasongko, N. (2019). A Compassionate Space-making:

Toward a Trinitarian Theology of telah mengkonstruksi sebuah konsep dan model kepemimpinan bersahabat berdasarkan tinjauan atas pemikiran Liz Carmichael dan Steve Summers, serta penilaian kritis atas warisan teoretis Robert Greenleaf tentang kepemimpinan. Bahkan, juga telah menemukan implikasinya bagi diskursus kepemimpinan kristiani dalam komunitas gereja melalui empat karakter pemimpin bersahabat.

Semakin jelas bahwa persahabatan Kristen dimulai dari kasih persahabatan yang tertulis dalam Alkitab melalui kisah percakapan Yesus dan dua belas sahabatNya dan kesadaran bahwa zaman ini tidak lagi menekankan subordinasi. Diskusi ini tidak akan berkembang apabila tidak ada para teolog kontemporer yang menstimulus tema persahabatan dengan menyoroti dimensi kasih Kristen. Oleh karena itu, penelitian ini membuka ruang kemudian terhadap analisis dan refleksi teologis menyoal karakter kepemimpinan bersahabat dengan meneladani Kristus, Sang Pemimpin Agung yang bersahabat.

Kepemimpinan kristiani telah sangat lama didominasi oleh konsep pemimpinpelayan, karena itu diperlukan cakrawala alternatif model kepemimpinan yang lebih bersahabat. Konsep ini akan berjalan apabila para pendeta mengejawantahkan keempat karakter pemimpin bersahabat yang ada. Dengan demikian, melalui konsep kepemimpinan bersahabat yang terlihat dalam karakter pemimpin bersahabat, para pemimpin di tengah komunitas gereja-gereja Kristen di Indonesia dapat memperjuangkan sifat kasih Ilahi dalam kehadiran mereka di tengah jemaat maupun marketplace agar teladan persahabatan Yesus termanifestasi secara dekat.

Friendship. The Ecumenical Review, 71(1-2), 21-31.

Adiprasetya, J. (2018). Pastor as Friend: Reinterpreting Christian Leadership. 
Dialog, 57(1), 47-52.

Apriano, A. (2018). Pelayanan Bersama

Komunitas Sebagai Model Pelayanan Pastoral Berbasis Paradigma Komunal-Kontekstual dalam Teologi Pastoral. Kurios: Jurnal Teologi dan Pendidikan Agama Kristen, 4(2), 92106.

Aorora, D. (2009). Konsep Kepemimpinan Servant Leadership Pada Institut Pertanian Bogor. Skripsi SE., Bogor: Institut Pertanian Bogor.

Blanchard, K. \& Hodges, P. (2003). The Servant Leader: Transforming Your Heart, Head, Hands \& Habits. Nashville: Thomas Nelson Inc.

Blanchard, K. (2002). The Heart of Leadership. In Larry Spears \& Michele Lawrence (Eds.), Focus on Leadership: Servant-Leadership for the Twenty-First Century (pp. ix-xii). New York: John Wiley \& Sons Inc.

Brown, N. A., \& Barker, R. T. (2001). Analysis of the communication components found within the situational leadership model: Toward integration of communication and the model. Journal of technical writing and communication, 31(2), 135-157.

Carmichael, L. (2004). Friendship: Interpreting Christian Love. London: T\&T Clark.

Engestrom, T. \& Dayton E. (1976). The Art of Management for Christian Leaders. Texas: Word Books Publisher.

France, R. T. (2007). The gospel of Matthew. Grand Rapids: Eerdmans Publishing.

Gibbs, E. (2010). Kepemimpinan Gereja Masa Mendatang (T. Siahaan, Trans.). Jakarta: BPK Gunung Mulia.

Greenleaf, R. K. (2002). Servant Leadership: A Journey into the Nature of Legitimate Power \& Greatness. New Jersey: Paulist Press.

Hendriks, J. (2002). Jemaat Vital \& Menarik. Yogyakarta: Kanisius.
Jackson, J. C. (2016). Conversation, Friendship and Transformation: Contemporary and Medieval Voices in a Theology of Discourse. New York: Routledge.

Lee, H. (1989). Effective Church Leadership: a practical sourcebook. Minneapolis: Augsburg Fortress.

Levering, M. (2007). Friendship and Trinitarian Theology: Response to Karen Kilby. International Journal of Systematic Theology, 9(1), 39-54.

Pakpahan, B. J. (2017). To Remember Peacefully: A Christian Perspective of Theology of Remembrance as a Basis of Peaceful Remembrance of Negative Memories. International Journal of Public Theology, 11(2), 236-255.

Mclntyre, P. (2012). [Review of the book Exploring Its Implications for the Church in Postmodernity, by $\mathrm{S}$. Summers]. Denver Journal, Apologetics and Ethics, 15. Retrieved from https://denverseminary.edu/thedenver-journal-article/friendshipexploring-its-implications-for-thechurch-in-postmodernity/.

Spears, L. C. (2002). Tracing the Past, Present, and Future of Servant Leadership. In L. C. Spears \& M. Lawrence (Eds.), Focus on Leadership: Servant-Leadership for the Twenty-First Century (pp. 1-18). New York: John Wiley \& Sons Inc.

Spears, L. C., \& Lawrence, M. (Eds.). (2016). Practicing servant-leadership: Succeeding through trust, bravery, and forgiveness. San Fransisco: John Wiley \& Sons.

Summers, S. (2009). Friendship: Exploring Its Implications for the Church in Postmodernity. London: T\&T Clark.

Roels, S. (1990). Moving Beyond Servant Leadership. Pasadena: De Pree Leadership Centre.

Ward, P. (2013). Liquid church. Eugenes: Wipf and Stock Publishers. 


\section{CATATAN AKHIR}

1. Definisinya sebagai berikut, "kepemimpinan kristiani ialah kepemimpinan yang didorong dengan kasih dan keinginan memberi diri untuk melayani. Kepemimpinan tersebut ditautkan dengan kontrol Kristus dan teladan yang telah Kristus berikan." Sementara itu Lee Harris menyatakan bahwa "seorang pemimpin kristiani yang memahami perannya sebagai pelayan secara spesifik melaksanakan tugasnya sebagai pemandu umat Tuhan dalam menuntun mereka memenuhi panggilan dan misinya" (Lee, 1989, p. 24).

2. Kecenderungan pemahaman tersebut didukung dengan publikasi terbaru Joas Adiprasetya (2018). Dalam Pastor as Friend: Reinterpreting Christian Leadership, Adiprasetnya menilai bahwa model pemimpin pelayan telah mendominasi pemikiran para pemimpin gereja di Indonesia sehingga sampai tidak ingin mempolarisasi model kepemimpinan lain yang bernilai Kristen.

3. Definisi yang adalah terjemahan pemikiran Greenleaf ke dalam bahasa Indonesia ini menjadi sangat umum. Bandingkan dengan Aorora (2009, p. 9).

4. Lihat pernyataan Spears (2002, p. 370). Pusat studi ini terletak di Indianapolis, Indiana, Amerika Serikat yang merupakan suatu lembaga pendidikan organisasi nonprofit yang mencoba mendorong pemahaman dan praktik kepemimpinan-pelayan. Telah terdapat di Australia/New Zealand, Kanada, Eropa, Korea, Filipina, Singapore, Afrika Selatan dan Inggris Raya. Pusat misinya adalah meningkatkan kepedulian dan kualitas seluruh institusi melalui kepemimpinan-pelayan. Wujud konkritnya ialah menyebarkan buku-buku, tulisan esai, dan video rekaman tentang kepemimpinan-pelayan. Untuk memperoleh informasi historis yang lebih lanjut, lihat Greenleaf (2002, pp. 369-370).

5. Beberapa kritik yang muncul setelah konstruksi ini diklaim sebagai yang terbaik di abad ini. Salah satunya antara lain oleh Gibbs
(2010, pp. 23-25). Gibbs menyatakan bahwa para pemimpin gereja tidak boleh terburu-buru menempatkan kepemimpinan yang menghamba sebagai konsep kepemimpinan gerejawi. Di dalamnya Gibbs mengutip Shierly Roels (1990, p. 3).

6. Carmichael menelusuri pemikiran Moltmann terkait pentingnya mendiskusikan persahabatan dalam konteks Afrika Selatan. Carmichael melihat sulitnya meletakan persahabatan, karena ia belum memiliki kesadaran atas itu. Karya Moltmann seakan menstimulasinya dalam membentuk konsep persahabatan Kristen (Summers, 2009, p. 1).

7. Untuk penjelasan lebih lanjut lihat Carmichael (2004, pp. 35-37). Carmichael menegaskan bahwa kita tidak dapat memungkiri ketika mendiskusikan kata kasih Kristen terdapat ragam bentuknya, yakni agape, eros, dan filia. Masing-masing memiliki karaterisiknya: agape merupakan kasih pengorbanan, eros merupakan kasih kegairahan. Namun fokus makalah ini ada pada filia, kasih persahabatan. Dengan demikian, penelitian ini akan menelusuri secara khusus filia sebagai basis persahabatan di sini. Menurut Carmichael kata sahabat, philos tidak mengundang kontroversi, namun menjadi dominan dalam Injil Yohanes (15:15; 11:11; 3:29; 19:12; 3 Yoh.15). Akan tetapi, Carmichael dalam bagian ini memusatkan perhatiannya pada filia yang secara eksplisit berada dalam Yohanes 15:13-15, secara khusus, "Aku tidak menyebut kamu lagi hamba, sebab hamba tidak tahu, apa yang diperbuat oleh tuannya, tetapi Aku menyebut kamu sahabat."

8. Sejak awal, Carmichael menandai bahwa penelusurannya akan terfokus kepada beberapa teolog klasik ini, terkhusus Aelerd dalam merumuskan spiritual friendship. Menurutnya, para teolog tersebut melihat persahabatan dari unsur kasih Kristen, terutama agape dan filia, meskipun keseluruhannya menyebutkan unsur kata Latin untuk menunjukkan kasih, yakni caritas sebagai dasar pembentukan arti persahabatan tersebut. Akan tetapi, fokus 
mereka menunjukkan bahwa kasih Kristen adalah persahabatan yang dapat melepas belenggu penghambat di dalam kehidupan, seperti dalam konteks Aelerd. Untuk analisis lebih lanjut lihat, Carmichael (2004, p. 71).

9. Di dalam bukunya Summers (2009, p. 198) memberi porsi atas karya Carmichael. Di dalam menjelaskan para teolog klasik ini, tinjauan dari McIntyre (2012), seorang teolog dari Sekolah Tinggi Denver relevan ditempatkan di sini. Di dalam tinjauan Mclntyre, Summers berangkat dari persoalan Agustinus tentang persahabatan Kristen sebagai jenis yang berbeda secara umum dari persahabatan yang benar. Summers memperlihatkan fokus yang lebih banyak dengan Aquinas dan sentralitas persahabatannya yang melihat relasi utama Allah sebagai yang utama dengan orang percaya. Bahkan, persahabatan di dalam tubuh orang percaya didasarkan kepada hubungan interpersonal Trinitas. Summers menjelaskan ide komunitas individual dan komunitas yang saling terkait. la mendasari pemahaman ini dalam teologi Ortodoks Timur dari pada teologi Barat yang cenderung hierarkis. la juga menandai bahwa lebih dekat persahabatan menjadi sangat signifikan di zaman biara dengan pola relasi setara yang terjalin didalamnya.

10. Fungsi pastoral yang dimaksudkan di sini bukan terbatas pada pelayanan pendeta, melainkan pelayanan pendampingan yang juga melibatkan komunitas gereja. Untuk definisi terdahulu dalam penelitian tentang hal ini dapat dilihat dalam Apriano (2018, pp. 92-106). 